\title{
Why Do People Hesitate? Perceived Risk in Workplace Spirituality
}

\author{
Haw Ran Wong (Corresponding author) \\ Graduate Institute of Business Administration, Fu-Jen Catholic University \\ 510 Jhongiheng Rd., Sinjhuang District, New Taipei City 25205, Taiwan \\ Tel: 886-2-2905-2000Ｅ-mail: hawranosc@yahoo.com
}

Jer San $\mathrm{Hu}$

Graduate Institute of Business Administration, Fu-Jen Catholic University 510 Jhongiheng Rd., Sinjhuang District, New Taipei City 25205, Taiwan

Tel: 886-2-2905-2000 E-mail: 074986@mail.fju.edu.tw

\author{
Received: April 18, 2011 \\ Accepted: June 1, $2011 \quad$ Published: November 1, 2011 \\ doi:10.5539/ijbm.v6n11p57 \\ URL: http://dx.doi.org/10.5539/ijbm.v6n11p57
}

\begin{abstract}
The importance of workplace spirituality was generally affirmed by past researches, based on the assumption of acceptance of the employees, where the phenomenon of passivity in the interaction was neglected. This research aimed to understand the phenomenon of hesitation that hindered the interaction of organizational spirituality, in a multi culture and religion context. This research used the qualitative method, particularly the in-depth interview and the grounded theory's coding methods. This research found that the multi-facet perceived risk concept was useful, where (1) five dimensions of perceived risk involved: time, social, psychological, functional and belief dimensions; (2) the dimensions and properties indentified were consistent to the findings of previous studies on social exchange and perceived risk theories, wherein the cultural factor had great influence; and (3) the perceived risk concept might be extended into organizational spirituality and a framework that consist of five dimensions and fourteen properties was proposed.
\end{abstract}

Keywords: Social exchange, Perceived risk, Spirituality, Workplace spirituality, Grounded theory

\section{Introduction}

Workplace spirituality is becoming an important issue in organization management, especially for organizations with strong service and mission orientation. This is due to the reason that the promotion of shared organizational spirituality to the employees can be seen as an integrative mechanism in the effort of aligning, educating and motivating employees towards the organizational values, objective and mission and enhancing the commitment to them (Rafiq \& Ahmed, 2000). Kolodinsky, Giacalone and Jurkiewicz (2008), have pointed out that positive attitudinal outcomes, such as organizational identification and work satisfactory, would be resulted from strong match between employees' values and their perceptions of the organization's spiritual values. Nevertheless, past studies though have affirmed its relevance and importance are generally focusing on its benefits to organizations and individuals, where an assumption is made on the acceptance of the organizations' members. The presence of hesitance in the participation of workplace spirituality is somehow neglected.

Spirituality is often introduced at the organizational level in different forms and degrees, rooted in the particular religio-cultural tradition and mission orientation of the institutions, which have formed part of the culture that differentiates them from others. These spiritual activities often aim not only at the passing on of the organizational tradition but also serve as an effort of transmitting the shared values and promoting the commitment to them, which is critical to the organizational performance and success. However, it is also observed that resistance and apathy to organizational spiritual activities seem to be not a rare phenomenon. In order for the values of the organization to be truly having impact, the issue of passivity must not be overlooked (Kolodinsky et al., 2008; Heaton, Schmidt- Wilk \& Travis, 2004).

Blau (1968) has advocated that social exchange is not concerned only with material gain but also with nonmaterial social experiences such as humanitarian ideals and spiritual values. Thus from the social exchange theory perspective, the phenomenon of hesitancy may be understood as people's tendency to maximize the perceived benefits and to minimize the perceived negative impact in facing an exchange. Molm (2003) has further pointed out that, although traditional social exchange theory has focus much on benefits maximization, the important role of risk and loss avoiding in the process of social exchange may be greater than they were thought to be.

This research would like to explore the possible factors behind the reluctances that hindered the interaction of organizational spirituality, especially in a multi culture and religion context. The concept of perceived risk is seen as a useful theoretical basis in this case, in relation to adoption and decision making. Workplace spirituality on the interactive level involves the process of accepting new values and practices, where the perception of 
possible un-favorability may exist. Further, the nature of spirituality, which is intangible, experiential, thus subjective and uncertain, may also add to the risk perceived (Cunningham, Gerlach, Harper \& Young, 2005). Therefore, focusing on the perceived risk perspective, this research intends to (1) identify the perceived risk dimensions involved, (2) clarify the nature of the constructs, and (3) extend the concept of perceived risk into organizational spirituality by proposing a workable framework, so that a more effective dialogue and communication can be established.

\section{Theoretical Background}

\subsection{Spirituality and Workplace Spirituality}

Although spirituality has been defined from various angles, Mohamed, Wisnieski, Askar and Syed, (2004) have approached it from the managerial and psychological perspectives. They have pointed out that from the managerial view, spirituality can be seen as the, 1) basic feeling of being connected with one's self, others, the transcendental and the universe; 2) a work feeling that energizes action; 4) values aimed at transcendence toward ultimate values; 5) the deeply held values that guide life and work practices; 6) the recognition of an inner life that nourishes and is nourished by meaningful work in the context of community; and 7) the way to achieve personal envisioned growth.

From the psychological perspective, it is 1) the response to God's call; 2) a way of being and experiencing due to the awareness of the transcendent dimension and values; 3) a transcendental experience in questioning the meaning of personal existence and attempts to place oneself within an ontological context; and 4) a subjective experience of the sacred. These complementary rather than mutually exclusive definitions; therefore, as McDonald (2000) has concluded, spirituality can be seen as consisting of five dimensions: 1) beliefs, attitude and perceptions; 2) transcendental experiences; 3) sense of meaning for existence; 4) belief in the paranormal; and 5) religious behavior and practice. These dimensions imply that spirituality would therefore touch on the psychological, the subjective and transcendent experiential, the beliefs and value system, and the behavioral and external expression aspects of a person.

As for workplace spirituality, in particular, it is pointed out that it involves the effort to find one's ultimate purpose in life, to develop a strong connection to coworkers and other people associated with work, and to have consistency between one's core beliefs and the values of their organization (Mitroff \& Denton, 1999). Further, it includes the recognition that there is an inner life that nourishes and is nourished by meaningful work in the context of community (Ashmos \& Duchon, 2000). The emphases here, besides inline with the previous understandings, are the relational and social aspects.

On the organizational level, workplace spirituality can be seen as the organizational core spiritual values that represent the philosophy of the organization, its priorities and sense of purpose that directly influence the organization's mission, goals and objectives, which provides the foundation for organizational practices and the context for thinking, acting and making decision (Milliman, Ferguson, Trickett, \& Condemi, 1999). Besides being related to well being, the individual motivation and task effectiveness, Gibbons (2000) has further pointed out that workplace spirituality is also related to organizational leadership, organizational climate, the change of culture, profitability through corporate values, the positive impact on the ability of organization in acquiring resources, and the improvement of ethical conduct of organization.

Workplace spirituality is thus seen as a complex and multi-faceted construct that includes three core dimensions: the "meaningful work", on the individual level; a "sense of community" on the group level; and in "alignment with the organization's values" and mission, on the organization level (Milliman, Czaplewski, \& Ferguson, 2003). In parallel, Kolodinsky et al. (2008) have suggested that there can be three conceptual understandings of workplace spirituality. At the most fundamental and individual level, it can be seen as the incorporation of one's spirituality and ideal in one's work setting. At the macro level, it refers to the organization's spiritual climate or culture, as it is perceived by the individuals the spiritual values within an organization setting.

Lastly, it can also be in an interactive mode, which reflects the interaction between the personal values and organizational values. Through the lens of the interaction between person and organization fit, workplace spirituality can be seen as a construct of perception that is based on the judgment of the congruence between the personal and the organizational values (Cable \& DeRue, 2002). However, in order for the values of the organization to be truly having impact, they must reflect the inner needs, belief and aspirations of the employees (Milliman et al. 1999).

\subsection{Risk and Risk Perception}

The Stanford Encyclopedia of Philosophy has suggested five specialized uses and meanings of the word risk, which are important and widely used across disciplines. They are the unwanted event which may or may not occur; as the cause of the unwanted event; as the probability of the unwanted event; as the statistical expectation value of the unwanted event; as the fact that a decision is made under conditions of known probabilities, which is a "decision under risk" as opposed to "decision under uncertainty". The same encyclopedia has also mentioned that some philosophers would insist on distinguishing the "subjective" and "objective" probabilities, whereas others reserve the term "probability" only for the subjective notion.

Hubbard (2007) has pointed out that uncertainty is the lack of complete certainty that is the existence of more than one possibility, where the true outcome, state, result or value is not known. Whereas risk, it is a state of uncertainty where some of the possibilities involve a loss or undesirable outcome. Risk thus generally may be 
independent from the notion of value itself. Although eventualities as such may include both the beneficial and adverse consequences, the more conventional usage focuses more on the potential negative impact. Risk perception, on the other hand, is referring to the subjective judgment that people make on the characteristics and severity of a risk.

Slovic, Fischhoff, Lichtenstein (1982) have found that the greater people perceived a benefit, the greater the tolerance for a risk. Slovic, Fischhoff, Lichtenstein (2000) have suggested that perceived risk is quantifiable and predictable. Coleman (1993) has argued that people will experience different levels of perceived risk resulting from their attitudes, beliefs, feelings, and cognitions about risk. Similarly, McClung (2002) has further pointed out that people's propensity to take risks not only depend upon the individual factors such as their personality and experience, but also the social and cultural factors such as being part of a group or having a family.

The social-anthropological approach has contributed significantly in this matter by posited that risk perceptions as produced and supported by social institutions such as institutions, cultural values, and ways of life (Wildavsky, Aaron \& Dake, 1990). Mellers, Schwartz and Cooke (1998) on the other hand has proposed that risk from social science perspective, is a social construct intended to help people to cope with and understand the dangers and uncertainties of life. Laura Adams (2005) has suggested that factors such as voluntariness, affective, and familiarity will affect the tolerance of risk.

Perceived risk is much discussed in the management fields, especially in relation to the adoption and choice decision making. Many have found that perceived risk is a useful framework in the study of the acceptance of product and services (Cunningham et al. 2005; Mitchell 1999). The term perceived risk means the individual's subjective belief about potentially negative consequences from one's decision or the possibility of a loss in pursuit of a desired outcome. The word "perceived" is used in contrasting to the objective outcome one is associated with (Samadi \& Yaghoob-Nejadi, 2009).

Mitchell and Harris (2005) have pointed out that perceived risk can be conceptualized as a multi-dimensional subjective expectation of loss, e.g. financial risk, the potential money loss associated with the purchasing; psychological risk, the potential loss of self-image or self-concept; social risk, the possible loss of esteem, respect and friendship; time risk, the potential loss of time and effort associated; physical risk, the potential threat to the health or appearance of the customer; and functional or performance risk, the potential loss due to item failure after purchase.

Laroche, McDougall, Bergeron and Yang (2004) have further highlighted that the dimensions of risk are very setting specific. In the case such as the adoption of two different products or services, though both may incur risk, due to the differences in nature, risk may incur from different dimensions. It is suggested that factors such as intangible, non-standardized, without guarantees and the need to be experienced before can be assessed, may contribute to the risk perception (Cunningham et al. 2005). Laroche et al. (2004) have further made a different between physical and mental intangibility, where the latter is related to the uncertainty in the mental representation of a good or service. People who are unable to develop a mental representation of a product or service will have difficulty evaluating it regardless of whether it has a physical presence or not. The same authors also propose that the risk dimensions will affect the type of information sought, the information sources used, and the length of time needed in the decision process. The implication is that the communication and marketing strategies used to reduce risk will be far more effective if the contributions of each of the risk dimensions are well understood.

\section{Research Method}

This research intended to explore why people hesitate to participate in workplace spirituality and what would be the possible factors behind, where qualitative data were involved. Thus this research used the qualitative research method in particularly the in-depth interview method, where semi-structured questions were formed and applied in the interviews and for data collection. Neutral questions such as, "Generally, how would others react toward these activities?" and "Why do you think they reacted in such a way?" etc., were used as guiding questions; the interviewees were encouraged to express their own opinions, the individual tangents of thoughts were followed when interview proceeded. People tended to answer at first in a more general and superficial manners, further questions were needed in order to probe into the deeper factors.

The questions would be formed in a third party manner to avoid the possibility of self-defense mechanism and to facilitate the projection of one's thoughts and feelings onto others. Since workplace spirituality was a rather abstract concept, the research would use concrete activities as example for the workplace spirituality. The spiritual activities use as examples in the questions are the activities earlier observed and grouped by the researchers according to their characteristics. The first group of activities, such as the Morning Prayer meeting, was seen to be more general and directly related to the religious tradition of the organization. Second, the festive celebrations too were spiritual activities more common and in-lined with the local and cultural traditions, whereas the third group, the spiritual care and support activities, were more of personal and small group activities. These activities were in line with the five dimensions suggested by McDonald (2000).

Since the purpose of this research was to understand the hesitant factor of workplace spirituality acceptance, on the interactive level, in a multi-culture and religion context, the in-depth interview was conducted with the employees of a religious run hospital in the multi-culture and religion context of Taiwan. The hospital was a regional teaching hospital consisted with 1100 personnel, including Taiwanese, Italians, Filipinos, Burmese and 
Aborigines and other ethnicities. The employees of the hospital were also from different religious background, including Catholics, Protestants, Buddhist, local folk religions and Muslim. However, due to the reason that the hospital was run by the Catholic missionary, the spirituality communicated were more of spirituality of Christian traditions.

Theoretical sampling was used, with the aim to gain deeper understanding of the analyzed cases and to facilitate the development of analytic frame and concepts. It was to maximize the opportunities to compare incidents or happenings, and to determine how a category, in this case the possible risk perceived, varied in terms of its properties and dimensions. Theoretical sampling involved a process where the representativeness of concepts, not of persons was crucial. That was to say, the units of analysis were concepts, and the representativeness was of the theoretical complexity of the phenomenon being described. Therefore, the focus of sampling was on the hesitant happenings rather than the number of person. In this research participants for the follow-up in-depth interview were selected according to the following criteria that data: either confirmed in some way ideas that were emerging (typical case) or their data offered an insight deemed to be atypical in the context of what was being theorized and; whether typical or atypical, required confirmation and verification and; could be compared with participants in other settings (Tuckett, 2004).

The sampling would stop when the theory was saturated, where no new or relevant data seemed to emerge regarding a category. The category development was dense, insofar as the exemplar elements were accounted for, along with variation and process. The decision that data saturation or data redundancy had been reached was facilitated through constant comparison of data (Glaser 1999). This research interviewed 42 employees (including doctors, nurses, technicians, administrative staffs) who had some knowledge about the spiritual activities of the hospital and were chosen randomly; and were from different departments, religious backgrounds, positions, ethnic group, age groups and genders. Among whom 27 were female and 15 were male, age ranging from 24 to 60 .

The data of interview was collected in the form of either verbatim or memo by two experienced interviewers. The research mainly adopted the grounded theory's open coding and axial coding as its major coding methods. As pointed out by Strauss and Corbin (1998), coding was the operations by which data were broken down, conceptualized, and put back together in new ways. It was central to theories building on data. In open coding, the research named and categorized phenomena through close examination of the data. Data were broken down into discrete parts, which were compared and questioned with the "what, where, how, when and how" questions. Open coding thus broke down data into concepts and categories. Then data were compared and similar incidents would be grouped together and given the same conceptual label. Concepts were then be grouped at a more abstract level termed categories, such as the individual risk properties. Following that, the axial coding process involved forming an overall theoretical understanding of the phenomenon that was being investigated by finding relationships among categories. A conceptual category was developed and it represented an array of categories. The categories (risk properties) that belonged to that conceptual category (risk dimension) were referred to thereafter as subcategories (Smit, 2002). The processes of open and axial coding were iterative and back-and-forth, whereby details from the analysis informed further directions for sampling and discussion during subsequent interviews with different participants. The perceived risk framework of Mitchell and Harris (2005) was used as a major reference. The data from the interview was then divided into descriptions, risk properties (sub-categories) and risk dimensions (categories). A preliminary categorized data with the original transcripts will be set for triangulation.

\section{Results}

Based on the perceived risk theory framework, where perceived risk was defined as the "individual's subjective belief about potentially negative consequences from one's decision or the possibility of a loss in pursuit of a desired outcome", this study was able to abstract the five possible perceived risk dimensions, by using the framework proposed by Mitchell and Harris (2005) as a main reference. In addition this study also abstracted properties of the each dimensions: respect, belonging, social pressure and friendship; self-esteem and self-concept; content, formal expression and experience; timing, frequency and duration; usefulness and effectiveness.

The research first gathered ideas that were related to the inter-personal relationship under the concept of social. The interviewees had mentioned ideas such as: to avoid feeling odd and enjoy the company of colleagues, they would participate in the activity. On the negative side, one considered not to participate because of rejection or having conflict with the authority or the promoter of the activity. All the mentioned ideas were in relation to the others. They involved the factors of the sense of respect from others or for others, the sense of belongingness to a group, friendship with others or due to social pressure from the others. Thus, the research found that they could be grouped under the concept of social.

The second category identified was formed under the concept of psychological. The feelings of being forced, guilt and ashamed were mentioned in the interviews. These feelings that one tried to avoid seemed to point to the direction that personal assertiveness and self- love were involved. Some mentioned that they were not the particular type of person who would participate in spiritual activities. Other would feel that they were not up to the standard for the activities. The self-concept element could be identified in this case. Further, the unwillingness to be identified with those one did not approve, which involved the property of self cognition, was also reflected. For the activities that were more personal, such as in pastoral care for staffs, the reaction of feeling 
embarrassed or shy, due to being unaccepted or unable to be understood by others were mentioned. Therefore, they were placed under this concept of psychological, where they were more of the aspects within a person, how one perceived one's self, where the properties of self-esteem and self-concept involved.

The third category identified, which was parallel to the previous studies, was the category formed under the concept of temporal. Here it included the three properties of timing, frequency and duration. In the interviews, some thought that the time taken for the activities was too long and some would think that the timing was not right. Some mentioned the reason for not participating in those activities was due to not wanting to be "restrained", which was pointing to the timing and frequency of the activities introduced. The temporal elements were rather clearly and easily indentified.

The fourth category was formed under the concept of functional, or rather the practicality of how useful and how effective the activities were. These were the two questions often raised in the participation in the spiritual activities. In the interviews they came in expressions such as: did not have such need, not helpful, not effective, etc. There were also opinions that were more positive, where people felt the activities were useful. From these, they were placed under the concept of functional.

There was another category identified from the interviews which was not mentioned by the previous studies. They were more related to the value or belief system of a person. Opinions such as one would hesitate to participate due to the difference in religious belief. One felt unable to obtain resonance and thus felt that the activities were meaningless. Meaningfulness and consistency in terms of value and the expression of belief were also often raised as concerns by the interviewees. One might feel that the value or belief communicated was inconsistent to the value one owned, such as believing in to "serve without counting the cost". All these were placed under the concept of beliefs, where it included the three properties of the content, the formal expression and personal experience. The data from the interviews could therefore group under the concepts as shown in Table 1 below: refer to appendix: Table 1

As it was observed, the complexity of the perceived risks was threefold. First, the perceived risk might be seen as a multi-dimensional concept. Second, an individual might reluctant to participate in organization's spiritual activities by different aspects of risk simultaneously. Last, the risks involved might share some similar characteristics, which could be easily confused if without further clarification, such as "wasting of time" might refer either to the timing or effectiveness.

\section{Discussions}

From the managerial perspectives, the promotion of organizational spirituality to the employees can be seen as an integrative mechanism in aligning, educating and motivating employees towards the organizational values, objective and mission and enhancing the commitment to them (Rafiq \& Ahmed, 2000). However, the communication of organizational spirituality touches on the social, psychological, belief, temporal and functional elements, has confronted employees with new set of ideas and practices, where the employees subjectively believe that there are potentially negative consequences from their decision or loss in pursuit of a desired outcome. These findings correspond to the general understanding of the researches on adoption or choice decision making, and social exchange theory (Molm, 2003; Mitchell, 1999; Mellers, Schwartz \& Cooke, 1998).

Due to the nature of spirituality, which is intangible, experiential, thus subjective and uncertain of its result, may further contribute to the risk perceived, as proposed by Hubbard (2007). In a multi-culture and religion context, the different values and expression of beliefs may also contribute to the uncertainty on what to be expected in the process. Additionally, McDonald (2000) points out that spirituality involves the psychological, behavioral, inter-relational, value and transcendental aspects of a person. Therefore the social, psychological and beliefs dimensions of risk perceived, as identified in the interviews, corresponds well to the nature of spirituality.

The temporal risk perceived is related to the potential loss of time and effort associated. The temporal dimension identified is consistent to the findings of previous studies on adoption and choice decision making (Ko, Jung, Kim \& Shim, 2004; Khan, 2010). In this research there are three different properties observed. First the "timing", people sometimes feels that the time is not right, there are other things they ought to do. Secondly, it is the "duration" or the amount of time needed. The third is the "frequency" of an activity. The time people feel "reasonable" and "acceptable" is often subjective, which management should take note of in organizing activity. The "importance" mentioned is relative to particular time, which is different from the one in the functional dimension that is more on usefulness.

The category of psychological risk identified in this research is related to the potential loss of self-esteem and self-image; thus two properties are involved. A person feels that one's participation in certain spiritual activities encouraged by the organization will somehow affect one's self-esteem or self concept. In some cases, this may come from the sense of being like those people whom one did not approve. In other cases, this is also identified as the feeling of "guilt", for being too close to other tradition or religion in contrast to one's own. A person may also risk with the feeling of been "forced", which affect one's self-esteem to act according to one's desire, or into doing things that might contradict one's self-concept. This is consistent to the findings of Lawler (2001), who pointed out that emotions were central to the social exchange process. Individuals should be conceptualized as emotional and not cognitive alone. Emotions as the internal reinforcements or punishments are related to individuals' relational and group attachment (Lawler, 2001). The act of empathy may be helpful in reducing the perceived loss of self-concept or self-esteem. The psychological dimension is related to the intra-personal aspect, 
in contrasting to the social dimension.

Social risk in this research refers to the possible loss of respect, sense of belongingness and friendship. One may also risk in against the pressure from one's life circle. It is quite frequent that one will express that one feels odd if others are not doing the same or participating, especially those who are close to oneself. They feel the spiritual activities of a specific tradition are different from those of their close friends or family members' culture or tradition, therefore touching on their sense of belongingness. On the other hand, there are also cases where a person feel "forced" or "pressured" to participate by either their superior or colleagues. This dimension is therefore referring to the inter-personal relationship, which is in relation to the others, as contrast to the personal and internal psychological dimension. The promotion and adoption of organizational spirituality, as social exchange, shared the subjective, voluntary, reciprocal and relationship-oriented nature (Lavelle, McMahan \& Harris 2009; Gould-Williams, 2007). The properties of the social dimension of risk perceived such as respect, belonging, social pressure and friendship reflected well these above aspects.

Functional risk is more of the possible occurrence of unwanted results or effects. Those who perceived such risk feel that those activities are not coincide with their needs. Some express in the form of doubting the effect of such activities. Others will feel that their own spirituality is good enough and they do not think that these of the organization are better. This identified functional dimension is also parallel to the findings of previous researches on acceptance and choice decision making, especially in relation to product and service adoption (Ko, Jung, Kim \& Shim, 2004; Khan, 2010). However, this risk can sometimes be easily confused with the time risk. Some will simply use time as a reason in shunning the activities if they are not asked to clarify what they mean by it. In fact, it is the issue of usefulness or effectiveness.

Using the methods of open coding and axial coding, this research at once tries to abstract the data by referring to the proposed perceived risk framework, and open to possible new concepts and categories. The last category identified is the so called risk of belief, which is new category observed and introduced in this research. Here, the risk is about the possibility of unwanted inconsistency or contradictory of value, meaning, or belief that may occur. Some feel that to participate in the spiritual activities is possibly engaging in or adhering to values or belief that are inconsistent to one's own belief system. The findings are consistent to the observation of Coleman (1993) and McClung (2002).

There are three properties involved in this category of belief. They were the content or substance, the formal expression, and personal experience. The formal expression and personal experience properties are consistent to the work of Schmidt-Wilk, Heaton, and Steingard (2000), which are identified as the pure and the applied spirituality. However, here in this research, it is proposed that another objective content property of the spirituality could be further differentiated from the subjective experience and formal expression. The content property is objective in nature, as identified in this research. It consists not in the subjective perception of a person nor in the particular form of a practice or expression. Sometimes expression could be different but shared same content, such as the charity as an objective value can have various form of expression. The inconsistency perceived between the value and actual practice, which leads to reluctant in acceptance, may be an indication of this property of content and its importance. Further, one might also feel that the external and formal expression of the activities introduced is inconsistent to the expression in one's own culture, tradition, or religion, thus adding to the uncertainty perceived. Often, those who are able to detect the differences between the activities mentioned, such as the religious prayer meeting and general festive celebration, are somehow sensitive to the formal expression that has strong cultural connotation.

This research uses the word "value" in this case in a narrower sense of the transcendental values such as justice, harmony and love. Here, the research chooses the word "belief" to represent the faith system that one highly regarded, giving meaning to one's life and seen as guiding principle. Different from the psychological category, which is more about the internal self, the belief dimension will involve an external aspect, which can be a value, belief system or god. Similarly, it is different from the social category, which is related to the interaction and exchange with people. It involves one's awareness of and conviction on the transcendental or things beyond human order.

Therefore, the observation is consistent, in terms of temporal, psychological, social, and functional risks, with the framework proposed by previous researches on the adoption or choice decision making and social exchange theories. However, the previous studies have focused on the physical, psychological and social dimensions of a person without considering the spiritual aspect. The additional risk dimension on belief proposed in this research, as this research would argue, it is due to the specific nature of the spirituality or the spiritual activity itself, which touches on the value and belief aspects of a person.

Hofstede (1984) has defined culture as the collective mental programming of the mind which distinguished the members of one group or category of people from another. Among the four major dimensions of cultural values proposed by Hofstede, the uncertainty avoidance dimension is considered to be most important cross-cultural perspective of perceived risk, which reflects the culture's tolerance or intolerance of uncertainty. Besides the perception of risk in general, Ko, Jung, Kim \& Shim (2004) has observed that there are also significant differences in the perception of the specific risk dimensions in adoption decision making, which due to the existence of the cultural differences in response to the specific risk factors. The belief dimension of the perceived risk identified in the spiritual activities, particularly in relation to the properties of content, experience and expression, is consistent to these findings. 
Organizational spirituality not only touches on the value and belief of people but also subjective and experiential in nature. These characteristics make spirituality relativistic in the sense that it is based on people values and beliefs that may change from one culture to another. Culture (or subculture) is seen as having strong influence on the perception of risk and the relative importance of the various dimensions, by shaping the social interaction and through which the values, lifestyles and personalities of the people. The setting of a Catholic hospital in the Taiwan's cultural and religious traditions context in this study may specifically highlight the differences among the various forms of cultural traditions. Therefore it is vital in the process such as the promotion and adoption of organizational spirituality that involves high degree of interaction between people, where the cultural elements would have a great influence (Furrer, Liu \& Sudharshan, 2000).

Additionally, it is observed that the financial risk, which is one of the key dimensions in previous studies of perceived risk, is not observed in this study. This is probably due to the reason that the spiritual activities observed are generally offered free-of-charge. Furthermore, since the activities involved generally do not require the staffs to take an off from their works, people are not converting time into the financial term, and thus may be mixed with the "time" category. Therefore, the potential direct financial loss is not perceived explicitly.

Among the implications for management, first and foremost, is that the adoption of organizational spirituality should not be seen as neutral interaction but one that perceived a priori by employees as risky. Though it is vital for organization to convey its spirituality, which is critical for the diffusion of the organizational vision and mission, the various risk factors possibly perceived by the employees must not be overlooked. Laroche et al. (2004) propose that the perception of risk and its dimensions will affect the type of information sought, the information sources used, and the time needed in the decision process. Therefore information and its communication could be a major focus.

Chen, Chang and Chang (2004), suggested, from the marketing perspective, external cues could be useful means in reducing the risks perceived. They proposed that in reducing the feeling of insecurity, the perceptions of psychological risk way be reduced through empathy cues. Properties such as respect and friendship can be used as cues in lessening the perceived social risk. Further, cues such as flexibility, endorsed and effectiveness may be helpful in reducing the perceived temporal and functional risks, as indicated by previous studies. Thus, strategy that includes external cues in the communication of the organizational spiritual activity can be an area for future research to focus upon. In line with this, the using of common and familiar expressions and linking to the common values can be points to be considered. An important task of building a shared spirituality is critical in enhancing the shared value and goal of the organization. The substance of the value, though fundamental, is not the only factor involved. The external expression of the value would also play an important role in the interactive process. The employees feel "foreign" towards a value sometimes could be due to the failure of communication and handling rather than the value itself.

However, there are several issues remains. As a careful study of the interaction of workplace spirituality, this is by no way an exhaustive one. Although this study based it findings on in-depth qualitative studies on the perceived risk and its dimensions in the specific multi cultural and religion context of Taiwan, the ability to generalize needs further empirical verification. While this study has proposed a framework of perceived risk in relation to the various dimensions, this framework and its relation to the adoption of workplace spirituality, need further empirical testing and validation. Although this research has taken the perceived risk stance in approaching the phenomena of passivity towards organizational spirituality, it is observed that there are other possible factors that may contribute to the issue. Factors such as the effectiveness of communication; the capability of person in-charge to communicate; and the personal initiative could be some of the possible factors that may affect the interaction. These issues are not reflected in this research but would be interesting areas for future study to look into.

\section{Conclusion}

Organizational spirituality is vital in organization management, due to the fact that it is a crucial integrative mechanism in aligning, educating and motivating employees towards the organizational values, objective and mission, and enhancing commitment to them. It is in this sense that hesitation in the interaction of organizational spirituality should not be neglected. Basing on the Social Exchange theory that people can be greatly motivated by risk avoidance in exchange, thus to understand the phenomenon from the perceived risk perspective, that is understood as individual's subjective belief about potentially negative consequences from one's decision or the possibility of a loss in pursuit of a desired outcome, can be necessary. Building upon the past studies on workplace spirituality and perceived risk, this research has found that the risk perceived in the interaction of organizational spirituality consists of social, psychological, beliefs, temporal and functional five dimensions. Additionally, there are fourteen risk properties indentified, which are the elements upon which negative consequence and loss may occur. The proposed perceived risk framework can be seen as a useful conceptual framework in understanding the hesitation in the interaction of organizational spirituality. Managerially, this research provides management with the importance of the employees' risk perception and directions for the associated risk-reduction strategies in the interaction of organizational spirituality. The information or communication aspects, the use of external cues such as respect, empathy, meaning, flexibility and endorsement that correspond to the five risk dimensions, are seen as possible strategies to be focused upon. Culture has strong influence on the perception of risk and its dimensions, by shaping the social interaction. Therefore it is critical in the promotion of organizational spirituality to take into consideration the cultural elements. 


\section{References}

Ashmos, D.P., \& Duchon, D. (2000). Spirituality at work: a conceptualization and measure. Journal of Management Inquiry, 9 (2), 134-145. http://dx.doi.org/10.1177/105649260092008

Blau, Peter M. (1964). Exchange and Power in Social Life. New York, Wiley.

Cable, D. M., \& DuRue, D. S. (2002). The Convergent and Discriminant Validity of Subjective Fit Perceptions. Journal of Applied Psychology, 87 (5), 875-884. http://dx.doi.org/10.1037//0021-9010.87.5.875.

Coleman, C. (1993). The influence of mass media and interpersonal communication on societal and personal risk judgments. Communication Research, 20 (4), 611-628. http://dx.doi.org/10.1177/009365093020004006.

Cunningham, L., Gerlach, J., Harper, M., \& Young, C. (2005). Perceived risk and the consumer buying process: Internet airline reservations. International Journal of Service Industry Management, 16(4), $357-372$. http://dx.doi.org/10.1108/09564230510614004

Chen, T. Y., Chang P. L., \& Chang H. S. (2004). Causal Relationship among Cause Related Marketing, External Cues, Service Quality, Perceived Risk and Customer Value in Taiwan Banking Industry. Chiao Da Management $\begin{array}{lllll}\text { Review, } & 24 & \text { (2), } & \text { [Online] } & \text { Available: }\end{array}$ http://journalseek.net/cgi-bin/journalseek/journalsearch.cgi?field=issn\&query=1028-7310

Edward J. Lawler. (2001). An Affect Theory of Social Exchange. American Journal of Sociological, 107 (2), 321-352. http://dx.doi.org/10.1086/324071

Furrer, Olivier, Liu, Ben Shaw-Ching \& Sudharshan D. (2000). The Relationships between Culture and Service Quality Perceptions: Basis for Cross-Cultural Market Segmentation and Resource Allocation. Journal of Service Research, 2 (4), 355-371. http://dx.doi.org/10.1177/109467050024004

Gibbons, P. (2000). Spirituality at work: Definitions, measures, assumptions, and validity claims. Proceedings of the Academy of Management, USA.

Glaser B. (1999). The future of grounded theory. Qualitative Health Research, 9(6), 836-845. http://dx.doi.org/10.1177/104973299129122199

Hanjun Ko, Jaemin Jung, JooYoung Kim \& Sung Wook Shim. (2004). Cross-Cultural Differences in Perceived Risk of Online Shopping. Journal of Interactive Advertising, 4 (2), 20-29.

Heaton, D. H., Schmidt- Wilk, J., \& Travis, F. (2004). Constructs, methods, and measures for researching spirituality in organizations. Journal of Organizational Change Management, 17(1), 62-82. http://dx.doi.org/10.1108/09534810410511305.

Hofstede, Geert H. (1984). Culture's Consequences: International Differences in Work-Related Values, Newbury Park, CA: Sage Publications.

Hubbard D. W. (2007). How to Measure Anything: Finding the Value of Intangibles in Business. John Wiley \& Sons.

James J. Lavelle, Gary C. McMahan \& Christopher M. Harris. (2009). Fairness in human resource management, social exchange relationships, and citizenship behavior: testing linkages of the target similarity model among nurses in the United States. The International Journal of Human Resource Management, 20 (12), 2419-2434. http://dx.doi.org/10.1080/09585190903363748.

Julian Gould-Williams. (2007). HR practices, organizational climate and employee outcomes: evaluating social exchange relationships in local government. International Journal of Human Resource Management, 18(9), 1627-1647. http://dx.doi.org/10.1080/09585190701570700

Khan M. Sajid. (2010). Discriminating In-home Shoppers Using Perceived Risk: A Review and Analysis. Review of Business Research, 10(5), 162-171. [Online] Available: http://www.iabe.org/domains/iabe/journal.aspx?journalid=5

Kolodinsky, R. W. et al. (2008). Workplace Values and Outcomes: Exploring Personal, Organizational and Interactive Workplace Spirituality. Journal of Business Ethics, 81, $465-480$. http://dx.doi.org/10.1007/s10551-007-9507-0

Laroche, M., McDougall, G. H. G., Bergeron, J., \& Yang, Z. (2004). Exploring How Intangibility Affects Perceived Risk. Journal of Service Research, 6 (4), 373-389. http://dx.doi.org/10.1177/1094670503262955.

Laura Adams. (2005). Perspectives on Avalanche Risk: The Need for a Social Sciences and Systems Thinking Approach. In Avalanche News, 72, 1-7.

McClung, D.M. (2002). The elements of applied avalanche forecasting: The human issues. Natural Hazards, 25 , 111 - 129. http://dx.doi.org/10.1023/A:1015665432221.

McDonald Douglas A. (2000). Spirituality: Description, Measurement, and Relation to the Five Factor Model of Personality. Journal of Personality, 68 (1), 153-197. [Online] Available: http://www.wiley.com/bw/journal.asp?ref=0022-3506

Mellers, B.A., Schwartz, A., \& Cooke, A.D.J. (1998). Judgment and decision making. Annual Review of Psychology, 49, 447-477. http://dx.doi.org/10.1146/annurev.psych.49.1.447.

Milliman, J., Czaplewski, A. J., \& Ferguson, J. (2003). Workplace spirituality and employee work attitudes: An exploratory empirical assessment. Journal of Organizational Change Management, 16(4), $426-447$. 
http://dx.doi.org/10.1108/09534810310484172.

Milliman, J., Ferguson, J., Trickett, D., \& Condemi, B. (1999). Spirit and community at Southwest Airlines: An investigation of a spiritual values- based model. Journal of Organizational Change Management, 12(3), 221-233. http://dx.doi.org/10.1108/09534819910273928

Mitchell, V.W., \& Harris, G. (2005). The importance of consumer's perceived risk in retail strategy. European Journal of Marketing, 39(7/8), 821-836. http://dx.doi.org/10.1108/03090560510601789

Mitchell, V-W. (1999). Consumer perceived risk: conceptualisation and models. European Journal of Marketing, 33(1/2), 163-195. http://dx.doi.org/10.1108/03090569910249229

Mitroff, I.A., and Denton, E.A. (1999). A Spiritual Audit of Corporate America: A Hard Look at Spirituality, Religion, and Values in the Workplace. Jossey-Bass, San Francisco, CA.

Mohamed, A. A., Wisnieski, J., Askar,M., \& Syed,I,. (2004). Towards a Theory of Spirituality in the Workplace. Competitiveness Review, 14(1\&2), 102-107. http://dx.doi.org/10.1108/eb046473

Molm, Linda D. (2003). Theoretical Comparisons of Forms of Exchange. Sociological Theory, 21, 1-17. http://dx.doi.org/10.1111/1467-9558.00171

Rafiq, M., \& Ahmed, P. K. (2000). Advances in the internal marketing concept: definition, synthesis and extension. The Journal of Service Marketing, 14(6), 449-462. http://dx.doi.org/10.1108/08876040010347589

Samadi M, Yaghoob-Nejadi A. (2009). A Survey of the Effect of Consumers' Perceived Risk on Purchase Intention in E-Shopping. Business Intelligence Journal, 2, 261-75. http://dx.doi.org/10.1111/1467-6496.t01-1-00094

Schmidt-Wilk, J., Heaton, D.P., \& Steingard, D. (2000). Higher education for higher consciousness: Maharishi University of Management as a model of spirituality in management education. Journal of Management Education, 25(5), 580-611. http://dx.doi.org/10.1177/105256290002400505

Slovic, P., Fischhoff, B., \& Lichtenstein, S. (1982). Why Study Risk Perception? Risk Analysis, Vol.2, No.2, pp.83-93. http://dx.doi.org/10.1111/j.1539-6924.1982.tb01369.x

Smit Brigitte. (2002). Atlas.ti for Qualitative Data Analysis. Perspectives in Education, (20/3), 65-76. [Online] Available: http://search.sabinet.co.za/pie/

(2000). Facts and fears: Understanding perceived risk. In P. Slovic (Ed.), The perception of risk (pp. 137-153). London, UK: Earthscan Publications Ltd.

Strauss, A., \& Corbin, J. (1998). Basics of Qualitative Research - Techniques and Procedures for Developing Grounded Theory. Second edition, London, Sage Publications, 1998.

Tuckett, A. (2004). Qualitative Research Sampling-The Very Real Complexities. Nurse Researcher, (12/1), 47-61. [Online] Available: http://nurseresearcher.rcnpublishing.co.uk/

Wildavsky, Aaron \& Karl Dake. (1990). Theories of Risk Perception: Who Fears What and Why? American Academy of Arts and Sciences, 119(4), 41-60. [Online] Available: http://www.amacad.org/ 
Table 1. Perceived Risks Framework

\begin{tabular}{|c|c|c|}
\hline Dimensions & Properties & Descriptions \\
\hline Social & $\begin{array}{ll}\text { - } & \text { Respect } \\
\text { - } & \text { Belonging } \\
\text { - } & \text { Social Pressure } \\
\text { - } & \text { Friendship }\end{array}$ & 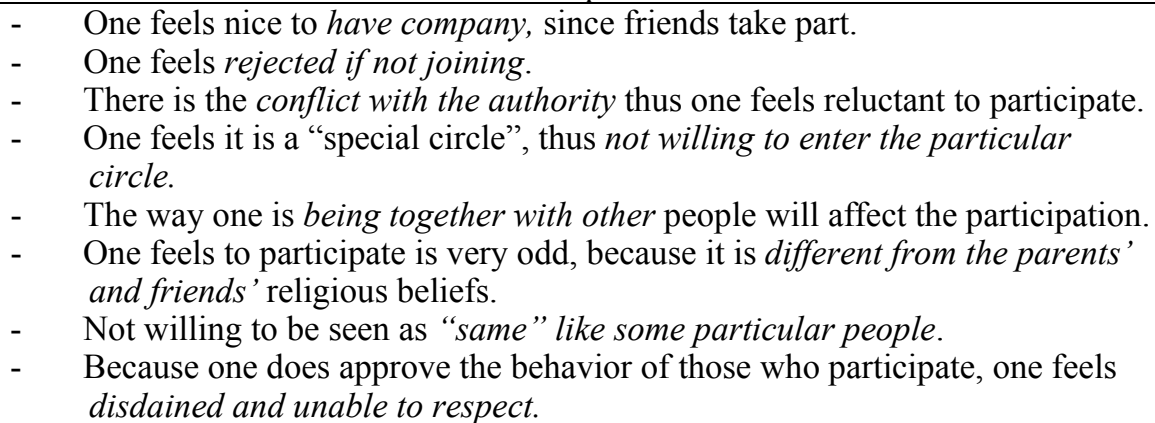 \\
\hline Psychology & $\begin{array}{ll}\text { - Self-esteem } \\
\text { - Self-concept }\end{array}$ & $\begin{array}{l}\text { - } \\
\text { - } \quad \text { When the beginning some participated with the feeling of being forced. } \\
\text { guilt. } \\
\text { - } \\
\text { Participating in the activity would make one feel ashamed to the religion one } \\
\text { believes in. } \\
\text { - } \quad \text { One feels one is not a spiritual person. } \\
\text { - } \quad \begin{array}{l}\text { One feels that one is not up to that standard yet. } \\
\text { - Shy, thought that one's own situation is different from others; others will not }\end{array} \\
\text { understand. } \\
\text { - One's sense of insecure in smaller group or in personal caring. } \\
\text { - } \\
\text { Does not approve some people's behavior, feeling disdained and unable to } \\
\text { respect; one would not want to be identified with them. }\end{array}$ \\
\hline Temporal & $\begin{array}{ll}\text { - } & \text { Timing } \\
\text { - } & \text { Frequency } \\
\text { - } & \text { Duration }\end{array}$ & $\begin{array}{l}\text { - } \quad \text { It is wasting of time. } \\
\text { - } \quad \text { Due to time factor, does not want to be restrained. } \\
\text { - } \quad \text { If the activity is in a holiday or after work, one may consider. } \\
\text { - } \quad \text { Some people will think that the time is too long; } \\
\text { - } \quad \text { Some people will think that the timing is not right. } \\
\text { - } \quad \text { The activity time is too long; has more important matter to attend to. } \\
\text { - } \quad \text { Unable to schedule, and will think that perhaps going to work and minding } \\
\text { family's matters are more important. } \\
\text { - Cannot commit oneself if too often. }\end{array}$ \\
\hline Functional & $\begin{array}{l}\text { - Usefulness } \\
\text { - Effectiveness }\end{array}$ & $\begin{array}{l}\text { - } \begin{array}{l}\text { One does not have the need, it will not be beneficial, if does not fit with the } \\
\text { - }\end{array} \text { Unction. } \\
\text { - } \quad \text { One comes with high expectation but found that the activity is ineffective. } \\
\text { - } \quad \text { Wasting one's time; thinking that the participation is without nourishment. } \\
\text { - } \\
\text { - } \quad \text { The activity is not useful to me; if it is useful I will participate. } \\
\text { re-energizing, settling- down, helpful for reflection. } \\
\text { - } \quad \text { Some would feel that the effectiveness of these activities is very important. }\end{array}$ \\
\hline Belief & $\begin{array}{ll}\text { - } & \text { Content } \\
\text { - } & \text { Formal } \\
& \text { Expression } \\
\text { - } & \text { Experience }\end{array}$ & 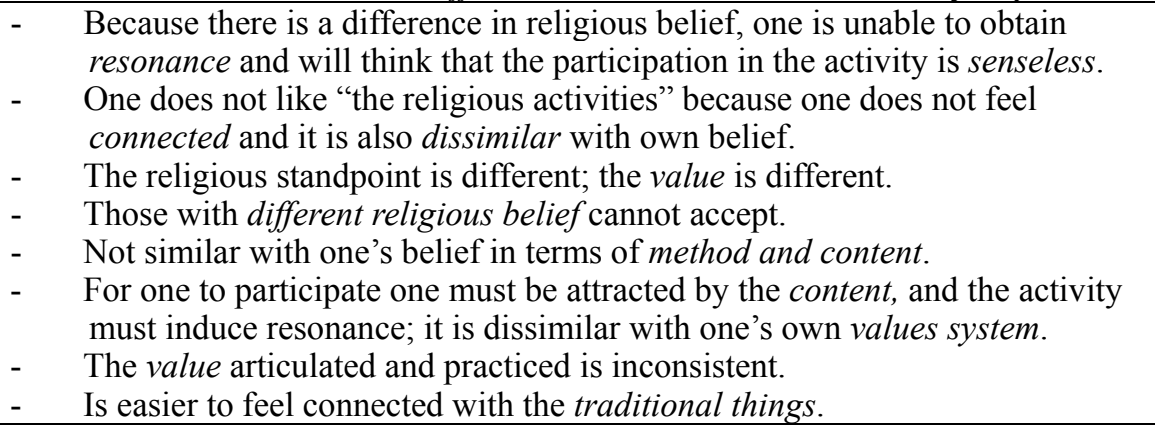 \\
\hline
\end{tabular}

